\title{
Ergonomic Risk Reduction Method in Aerospace Manufacturing
}

\author{
Shigeshi Yamashita \\ Department of Engineering, Tottori University, \\ Minami 4-101, Koyama, Tottori-Shi, Tottori, 680-8552, Japan. \\ Corresponding author: shigeshi_yamashita@mhi.co.jp \\ Kodo Ito \\ Department of Engineering, Tottori University, \\ Minami 4-101, Koyama, Tottori-Shi, Tottori, 680-8552, Japan. \\ E-mail: itokodo@tottori-u.ac.jp \\ (Received on February 9, 2021; Accepted on September 22, 2021)
}

\begin{abstract}
In the aerospace manufacturing, lots of processes cannot be automated and are performed manually by skilled workers. Because there exist some human error mistakes in such manual working processes, root cause investigations of these mistakes are indispensable and measures are implemented in working processes for preventing repetition of the same mistakes. Although skilled workers have strong confidence that they can complete their work with no mistake, there exist some cases that they cannot recognize their mistakes in practice. In such cases, root cause investigations cannot be performed and no measure is implemented. Such situation may become a serious risk in aerospace manufacturing because a tiny mistake can cause the serious mission failure of aviation system. To reduce such situation, the ergonomic risk reduction method is proposed. Skilled workers try to avoid frustration in performing their tasks and make mistakes through careless behavior. The cause of the frustration is discovered by ergonomic risk reduction method. Work risks can be removed by the progress of the working environment. Such risk reduction method contributes manufacturing organization resiliency. In this paper, we propose an ergonomic human error risk reduction method for skilled workers in Japanese domestic liquid rocket engine manufacturing.
\end{abstract}

Keywords- Human error, Human factors, Aerospace manufacture, Ergonomics, Resilient organizations.

\section{Introduction}

In Japanese aerospace companies, the quality of aerospace equipment depends on skills of workers because production work processes cannot be automatized and lots of fabrication and assembling workers are necessary in such companies. These equipment's are produced with small batch productions and cannot be invested greatly in the manufacturing process comparing to mass consumer products. Furthermore, because aerospace equipment must be high quality, skills of workers are emphasized and corporate managements actively supervise the competence of their workers to control qualities of their products. In aerospace equipment productions, work mistakes due to human error can lead to product defects, and defectives and reworks of products are major problem that increase manufacturing costs. Therefore, innovative methods and ideas which forecast such accidents effectively are craved because prediction efforts for preventing these accidents have been continuing and will keep continuing hereafter extensively.

When events which deviate from required design specifications occur, their causes are investigated and appropriate countermeasures are implemented which are called corrective actions and are compulsory by the quality management standard of the aerospace industry (IAQG, JAQG, 2016). Although recurrences of such events must be prevented by implementing countermeasures, recurrences of same events occur frequently in particular for skilled workers. Although this is 
entirely puzzling situation that skilled workers who have wealthy knowledge and long experiences cannot identify causes of their own mistakes, such situations occur frequently, causes of these events are concluded as "carelessness", some "cautionary notices" are added to manufacturing procedure manuals as countermeasures, and these countermeasures are completely useless for preventing recurrences.

Skilled workers behaviors can be categorized as "skill-based behaviors" from the view point of Rasmussen's SRK (Skills, Rules, Knowledge) framework (Figure 1) (Rasmussen, 1983). Because the work time becomes short and the variation of work is suppressed when a worker becomes proficient in a work and his or her proficiency level is improved, becoming skill-based behavior is desirable for producing high quality products stably and efficiently.

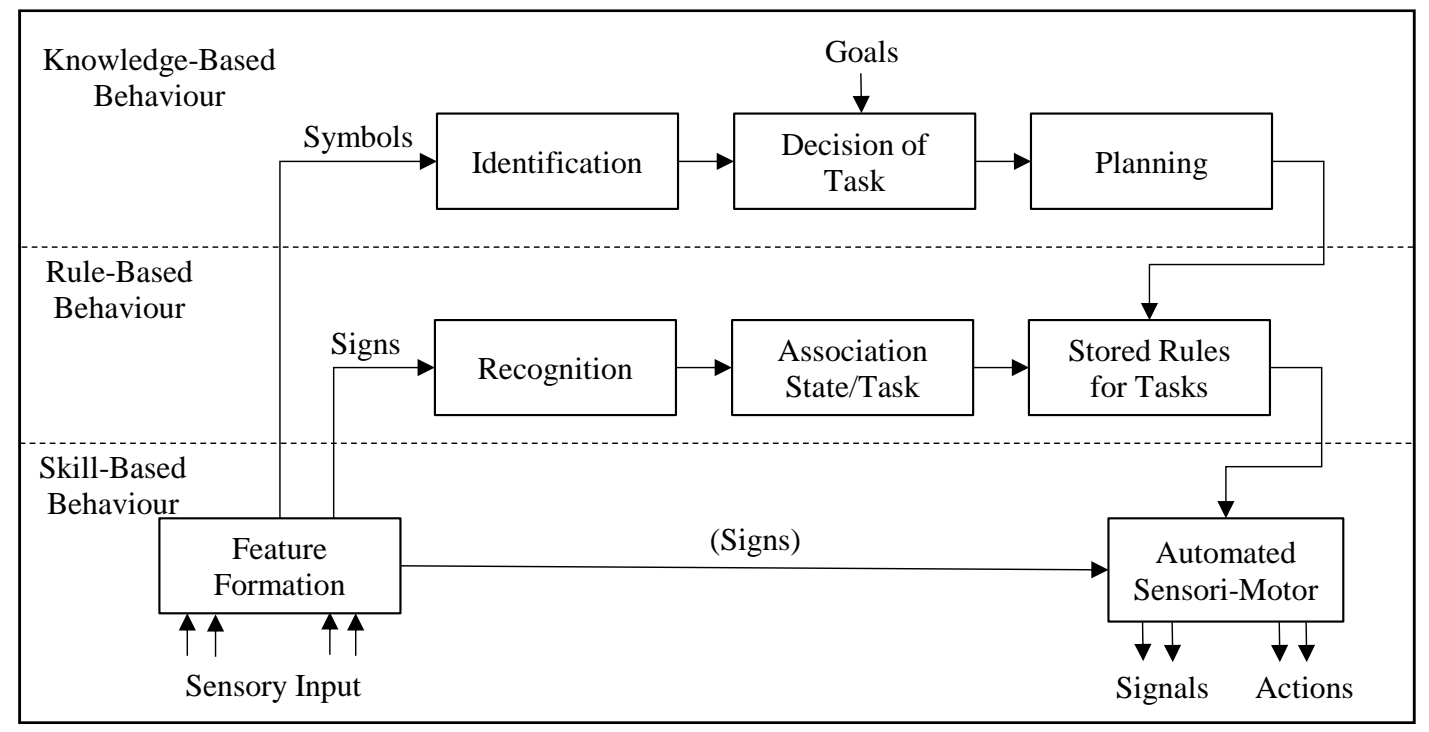

Figure 1. The Skills, rules, knowledge(srk) framework (Rasmessen, 1983).

Whereas, becoming skill-based behavior workers causes puzzling situation denoted above and such workers cannot identify causes of mistakes because they make their mistakes unconsciously. Skilled workers who have sufficient knowledge and experience can instantly determine procedures and forecast their results of given work tasks, and already have established their own pace when they perform their works. If something disturbs their works, they get frustrated and make mistakes during their works. Such errors of skilled workers which are caused by frustration-resolving behaviors based on the cognitive behavioral characteristics have already been reported (Komatsubara, 1999). Both physical and psychological stresses cause human error (Karino, 1985). The phase theory shows that stress (physiological state) caused by fatigue and monotonous work lowers consciousness and lowers human reliability (Table 1) (Hashimoto, 1984). Phase III "normal clear" indicates when you are concentrating and acting in an active psychological state, where errors rarely occur. However, this state cannot be maintained for a long time, and it will move to Phase II "normal relaxed" in a short time (about 10 minutes). Phase II is a relaxed, passive state of mind, and we believe that most of the time during work is in this Phase II. Tasks that rely on the skills of skilled workers need to be planned to be completed in the shortest possible time. In addition, for other work, it is necessary to develop a work environment that does not cause errors even in the 
mental state of Phase II. Although human error occurrence probabilities of skilled workers will decrease if fatigues and stresses of these workers are reduced, it is not realistic. Because skilled workers have strong confidence in their abilities, they are tended to solve their issues not by improving their surrounding situation but by themselves, root causes of human errors cannot be identified, effective countermeasures cannot be implemented, and human errors continue to occur.

Table 1. Phase theory (awakening level) (Hashimoto, 1984).

\begin{tabular}{|l|l|l|l|l|}
\hline & Consciousness Mode & Attention action & Physiological condition & Human reliability \\
\hline $\mathbf{0}$ & syncope & zero & Sleep, Sincope & 0 \\
\hline $\mathbf{I}$ & subnormal & Not expected & $\begin{array}{l}\text { Fatigue, Monotony, } \\
\text { Drinking, Drugs }\end{array}$ & 0.9 or less \\
\hline II & normal relaxed & Passive & Rest, break & $0.99 \sim 0.99999$ \\
\hline III & normal clear & Active & Positive & 0.9 or above \\
\hline IV & hypernomal & Conzentrate on one point & Panic & 0.9 or less \\
\hline
\end{tabular}

For reducing human error occurrence probabilities of skilled workers, safety and health activities are considered. In such activities, various kinds of hazards are predicted from ergonomics viewpoints, various kinds of risks caused by hazards are extracted, and countermeasures of risks are implemented. For preventing "safety and hygiene disasters", root causes concerning human errors are identified and countermeasures are implemented in safety and health activities. Similarly, for preventing "nonconformity events", root causes concerning human errors of skilled workers are identified and countermeasures are implemented in manufacturing. Ergonomic perspectives to make skilled workers aware of work risks are used. In this paper, we propose an ergonomic human error risk reduction method for skilled technicians in Japanese domestic liquid rocket engine manufacturing.

\section{Ergonomic Risk Reduction Method}

For reducing human errors during production of aerospace equipment, checklists are prepared. Such checklists are established at each workplace and are based on "ergonomic checkpoints". Checkpoints which are published by the International Labor Office (ILO) in collaboration with the International Ergonomics Association (IEA) are useful because more than 100 checkpoints are denoted (ILO, \& IEA, 2010). In this case, we use Kumashiro's "Workplace Improvement Checklist" (2008) and the human error factor of Japan Aerospace Exploration Agency (2017) because the ergonomic view point is emphasized. For skilled workers, the description of checklists is simplified, the total amount of them are limited, and whole checklists are reviewed by skilled workers to understand. The outline of the checklist is shown in Figure 2.

This checklist is designed to improve skilled worker's works physically and psychologically. As physical improvement cases, reductions of work risks such as the burden of back pain and muscle pain which are caused by unnatural worling postures, are reported by using checklists. As psychological improvement cases, avoidance of panic situations which are caused by a large amount of work concentration, and reduction of dangerous situations which are caused by 
continuous and monotonous works and the resulting degradation of the arousal level of the brain, are reported by using checklist. Checklist are ergonomically desigend to make workers aware surrounding risks and improve them. When checklists are used, it is necessary to arrange the usage of terms which are unique to each workplace. When checklist are used and any issue is discovered, it should be considered that an improvement has been found rather than thinking that a nasty problem has been found. It is difficult for skilled workers to find new risks in their workplaces where they have been accustomed for many years. For such workers, it is easier to find risks by expressing "the weight of the tool does not impose a burden on the work" rather than "the tool can be used properly".

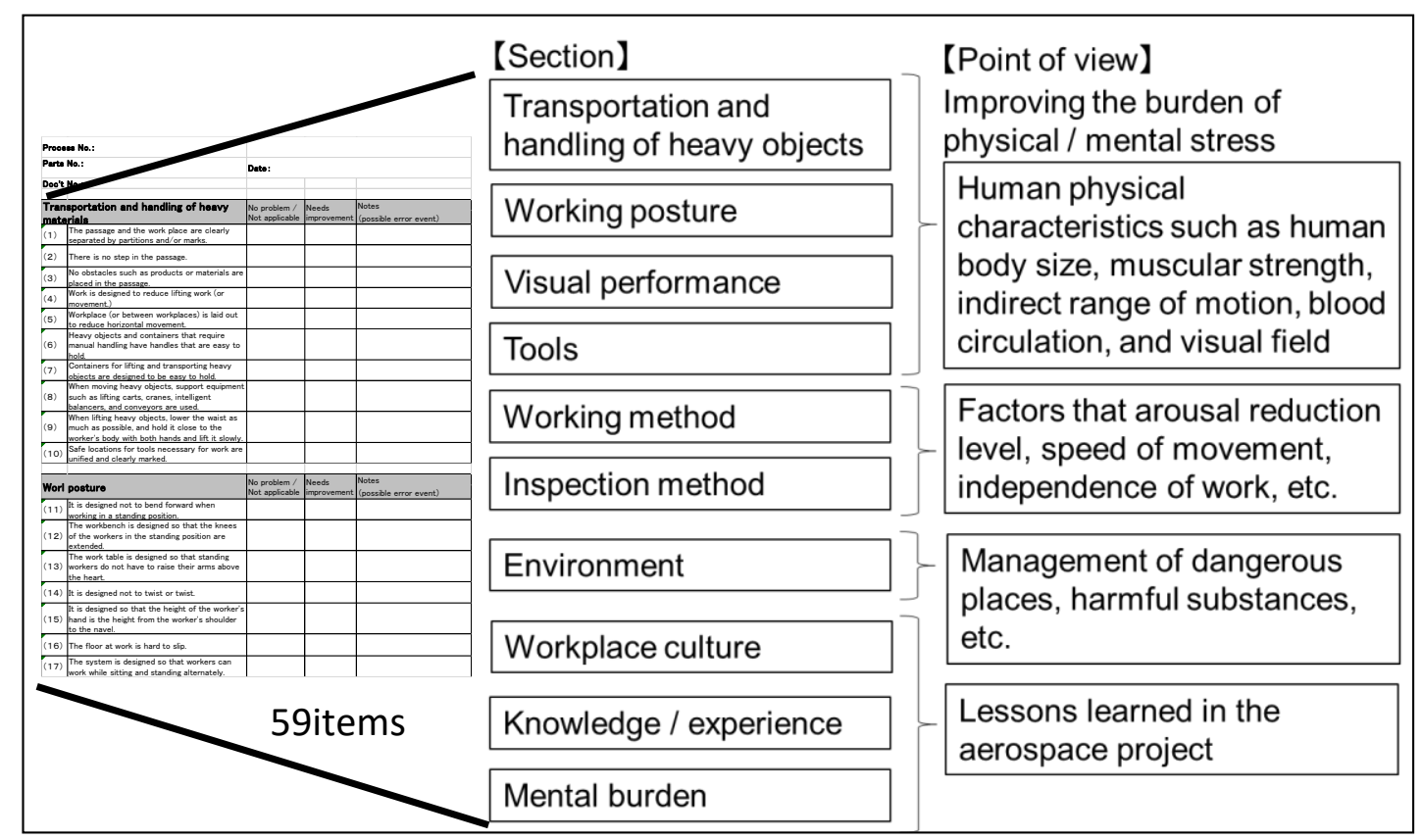

Figure 2. The outline of the check sheet.

\section{Demonstration In Space Product Manufacturing Process}

The effectiveness of checklists was confirmed through the installation work of orifices to gas pipe assemblies of a space equipment. 2-3 skilled workers had to handle about 40 components, an inspector confirmed the work quality, and it took about 4 hours until the end of work. Because these orifices adjust the designated flow rate of liquid in the space equipment, they had to be installed to pipe assemblies in a prespecified direction. In the work, a nonconformity which orifices were installed to pipe assemblies in a wrong direction (Figure 3) was reported and it was identified as a human error. The investigation board conducted the "why-why analysis" based on interviews of skilled workers and derived following results. 


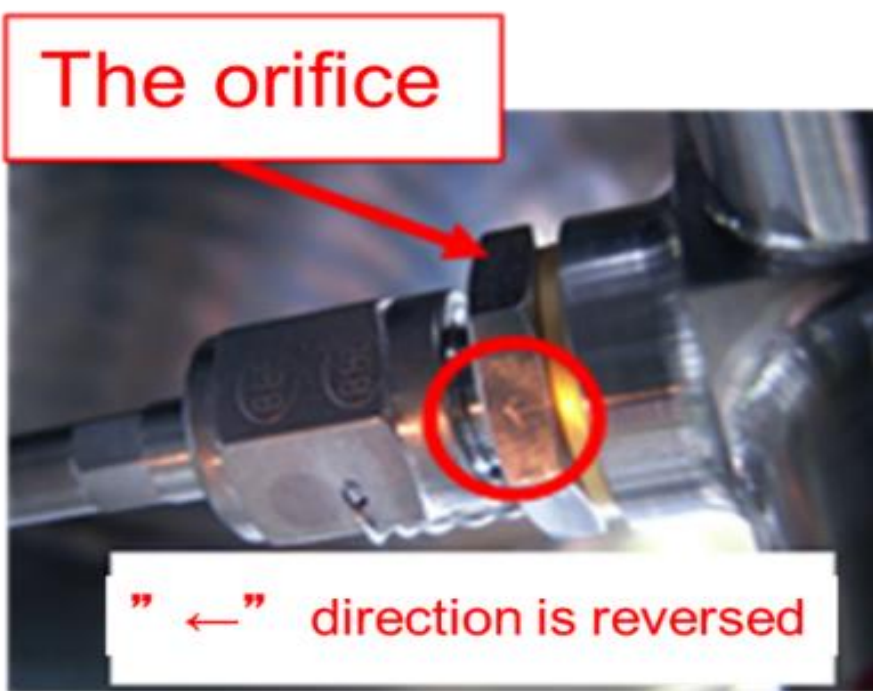

Figure 3. Orifice configuration.

Cause: Workers forgot to confirm directions of orifices after installation because they were worried about the back schedule of work.

Coutermeasures: Reeducation of skilled workers to reconfirm the importance of fundamental safety procedure.

Because skilled workers are supposed to have sufficient knowledge and mighty power of their work, causes of human error accidents are dismissed as a simple carelessness and further efforts for investigating the true cause of them cannot be made. Such phenomenon is known as the hindsight bias and prevents us to discover the true causes of human error accidents and to implement effective countermeasures for such accidents. From the ergonomic point of view, the risks of this orifice installation work are extracted. The installation work is constituted with 6 tasks (Figure 4):

(1)_The workers confirm the identification number of the orifices for installation and the tightening torque values which are specified in the work procedure manual.

(2)_The workers confirm the size of the orifice (flow path diameter) and the identification number of the seal from the drawing.

(3)_The workers bring the orifice and seals from the parts stand.

(4)_The workers bring the spanner and the torque wrench from the tool storage area.

5_The workers visually inspect the orifice thread, applies lubricant, sets the seal on the work desk.

6_The operator attaches the orifice to the pipe, tightens it to the specified torque, and checks the installation condition. 


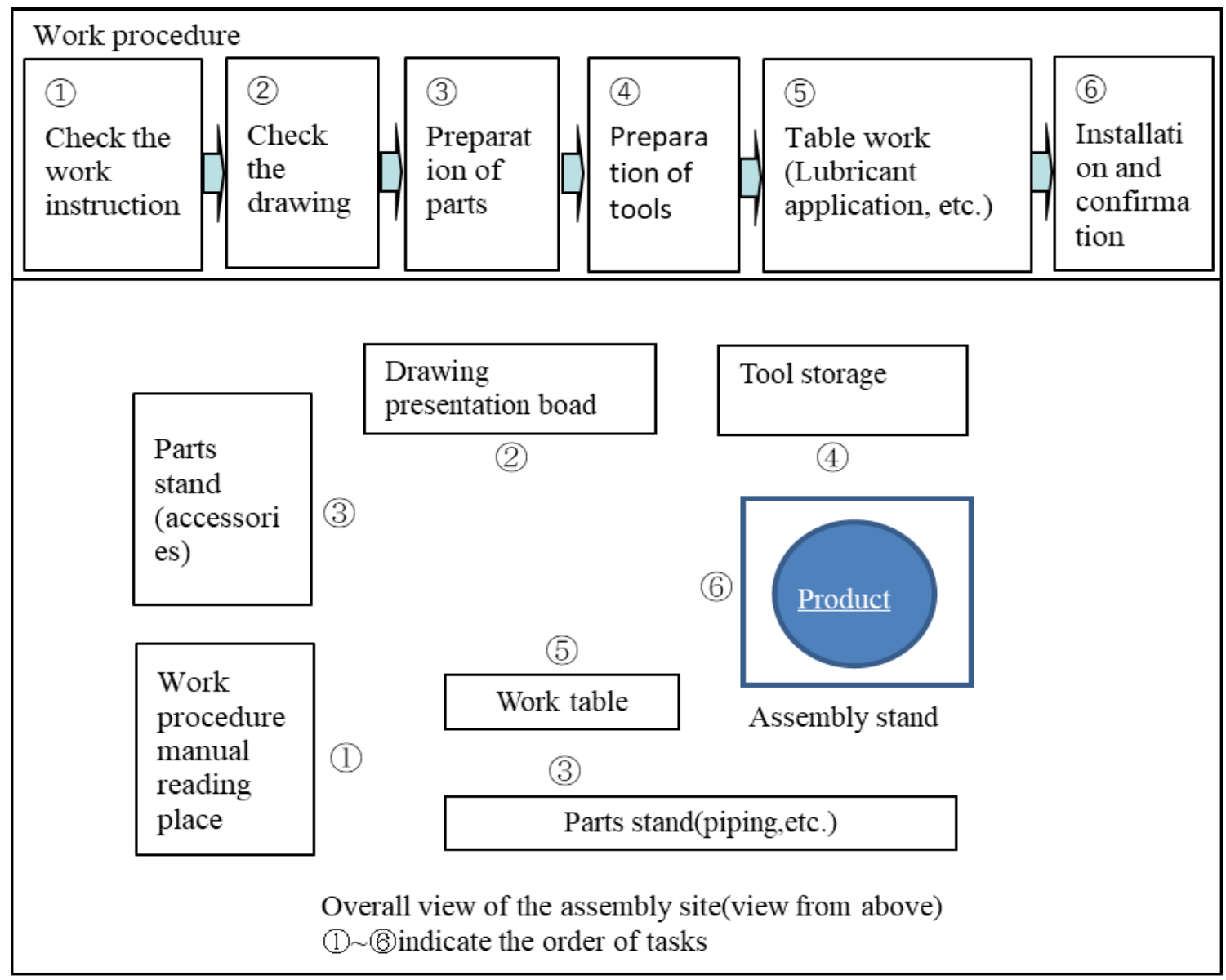

Figure 4. Gas piping system installation work outline.

Table 2 shows the risk extraction result which was performed from the ergonomic viewpoint by one of the authors and a leader of the workers. There exist ergonomic problems in 7 items in 59 items of 10 categories of checklists. The details of items are not be specified because of the state secret. These 7 items are summarized as following two issues and these issues become human error factors for workers.

(1) Work Procedure Manual (Table 2 No.26, 51)

Workers confirm their works by work procedure manual and the manual is difficult to use because the manual has 325 pages and it needs time to find a necessary procedure. For example, because the orifice installation work procedure is denoted on page 91 and the direction indication of orifices is denoted on page 212, workers have to flip through these pages during work (Figure 5). Although assembling procedure of gas piping is denoted on pages 87 to 95 and Figure on page 87 is important for assembling, the figure is not cited from page 212 and workers who refer page 212 may not notice Figure on page87.

Although Figure 4 shows there is only one manual in a workplace, there are two to three workers there and they may wish to read the manual at the same time because details of work procedure are 
denoted in the manual. When a worker reads the manual, other workers have to wait without doing anything. Because the manual is difficult to use, a worker who reads the manual needs long time as denoted above, paces of other waiting workers are disturbed, and they may get frustration in such situation.

Table 2. Trial result by check sheet (excerpt).

\begin{tabular}{|c|c|c|c|}
\hline Work method (common) & $\begin{array}{l}\text { No problem / } \\
\text { Not applicable }\end{array}$ & $\begin{array}{l}\text { Needs } \\
\text { improvement }\end{array}$ & $\begin{array}{l}\text { Notes } \\
\text { (possible error event) }\end{array}$ \\
\hline $\begin{array}{l}\text { There is a device to drop the processed and } \\
\text { assembled goods (be designed to make ending } \\
\text { motions easier). }\end{array}$ & & $\checkmark$ & $\begin{array}{l}\text { After the orifice is fastened, } \\
\text { sealing of the opening is } \\
\text { required to ensure cleanliness. }\end{array}$ \\
\hline $\begin{array}{l}\text { Using easily understandable signs or colors to } \\
\text { avoid mistakes. }\end{array}$ & & $\checkmark$ & $\begin{array}{l}\text { Difficulty seeing orifice arrow } \\
\text { markings. }\end{array}$ \\
\hline Work method (Inspection) & $\begin{array}{l}\text { No problem / } \\
\text { Not applicable }\end{array}$ & $\begin{array}{l}\text { Needs } \\
\text { improvement }\end{array}$ & $\begin{array}{l}\text { Notes } \\
\text { (possible error event) }\end{array}$ \\
\hline $\begin{array}{l}\text { Clear without ambiguity in the criteria for } \\
\text { testing or monitoring }\end{array}$ & & $\checkmark$ & $\begin{array}{l}\text { Although there is an arrow on } \\
\text { the orifice, the correct } \\
\text { direction at the time of } \\
\text { fastening cannot be } \\
\text { determined by looking at the } \\
\text { mating part. } \\
\text { There is a direction in the } \\
\text { procedure manual, but it is } \\
\text { hard to find the page. }\end{array}$ \\
\hline Workplace culture & $\begin{array}{l}\text { No problem / } \\
\text { Not applicable }\end{array}$ & $\begin{array}{l}\text { Needs } \\
\text { improvement }\end{array}$ & $\begin{array}{l}\text { Notes } \\
\text { (possible error event) }\end{array}$ \\
\hline $\begin{array}{l}\text { Understanding of space equipment and products } \\
\text { (Thorough maintenance of cleanliness, scratch } \\
\text { prevention, and recording) is sufficient. }\end{array}$ & & $\checkmark$ & $\begin{array}{l}\text { Work records are collected } \\
\text { later, not for each task. }\end{array}$ \\
\hline Visual & $\begin{array}{l}\text { No problem / } \\
\text { Not applicable }\end{array}$ & $\begin{array}{l}\text { Needs } \\
\text { improvement }\end{array}$ & $\begin{array}{l}\text { Notes } \\
\text { (possible error event) }\end{array}$ \\
\hline $\begin{array}{l}\text { The size and color of letters and numbers are } \\
\text { designed to prevent misreading. }\end{array}$ & & $\checkmark$ & $\begin{array}{l}\text { The orifice is marked with a } \\
\mathrm{P} / \mathrm{N} \text { and an arrow, but the } \\
\text { letters are small and hard to } \\
\text { see. }\end{array}$ \\
\hline $\begin{array}{l}\text { The object is placed so that the worker can see } \\
\text { the work object part without moving his neck. } \\
\text { (Use a visual field of } 60^{\circ} \text { or less as a guide.) }\end{array}$ & & $\checkmark$ & $\begin{array}{l}\text { From the viewpoint of the } \\
\text { worker, the orifice mounting } \\
\text { position is the back side of } \\
\text { the piping, and the visual field } \\
\text { is narrow. } \\
\text { (Marking cannot be seen } \\
\text { without a hand mirror } \\
\text { depending on the orifice phase } \\
\text { after fastening.) }\end{array}$ \\
\hline Burden of judgment & $\begin{array}{l}\text { No problem / } \\
\text { Not applicable }\end{array}$ & $\begin{array}{l}\text { Needs } \\
\text { improvement }\end{array}$ & $\begin{array}{l}\text { Notes } \\
\text { (possible error event) }\end{array}$ \\
\hline $\begin{array}{l}\text { The standards to be complied with are clearly } \\
\text { indicated or simply organized. }\end{array}$ & & $\checkmark$ & $\begin{array}{l}\text { The actual marking is small } \\
\text { and hard to see. There is a } \\
\text { diagram showing the } \\
\text { installation direction in the } \\
\text { procedure manual, but it is } \\
\text { difficult to find the page. }\end{array}$ \\
\hline
\end{tabular}




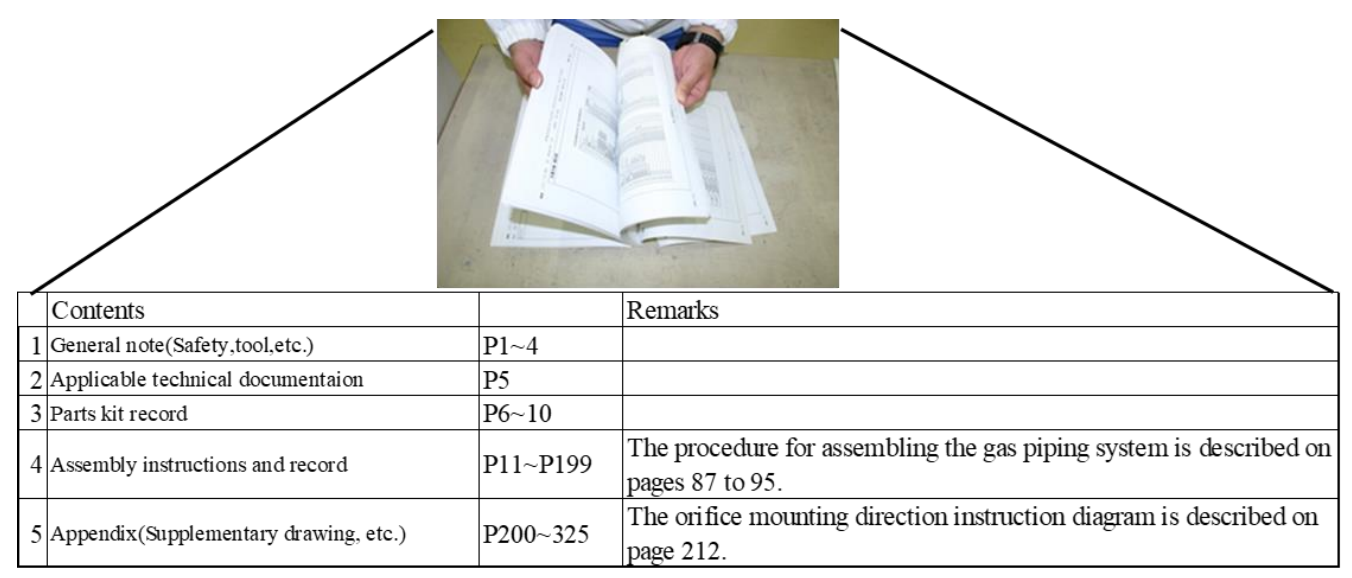

Figure 5. Work procedure manual.

\section{(2) Orifice Identification Marking (Table 2 No.24, 46, 48, 51)}

Although there exists an arrow marking on orifice which is engraved by vibro pens in a space with $3.8 \mathrm{~mm}$ width (Figure 6), confirming the direction of orifice is difficult for workers because the arrow marking is small and is hard to identify. Furthermore, workers cannot see orifices directly and can verify arrow markings on them by using mirrors during assembling works because lots of gas pipes of a space equipment are interlaced complicatedly (Figure 7).

The influence of (1) and (2) for skilled workers are considered and how they cause human errors are clarified as follows (Figure 8).

When workers confirm their works by work procedure manual and the manual is difficult to use, workers tend to avoid checking their work procedures by manual because checking the contents of different distant pages by flipping through them is troublesome work, and the work procedure 1 in Figure 4 cannot be adhered to. Workers rely on their own memories when they install orifices and work procedures from 2 to 4 cannot be adhered to. The occurrence probability of wrong direction installation increases because the shapes of IN and OUT of orifices are the same and orifices can be installed to pipes in either direction.

When two to three workers may wish to read the manual at the same time, workers tend to avoid checking their work procedures by manual because they wish to avoid disturbing their workflows. The work procedure 1 in Figure 4 cannot be adhered to and work procedures from 2 to 4 cannot be adhered to because workers rely on their own memories, and the occurrence probability of wrong direction installation increases.

When confirming the direction of orifice is difficult for skilled workers, the misidentification of orifice direction occurs frequently, the work procedure 5 of Figure 4 cannot be adhered to, and the occurrence probability of wrong direction installation increases. Although seal is installed on the inlet side of the orifices to prevent external leakage from the joint after orifice installed, there exists a possibility that this seal may be pasted in the opposite position due to misidentification of arrow markings. Because this seal can be identified much easier than arrow markings, workers tend to judge mounting directions by seal and the occurrence probability of wrong direction installation increases. 


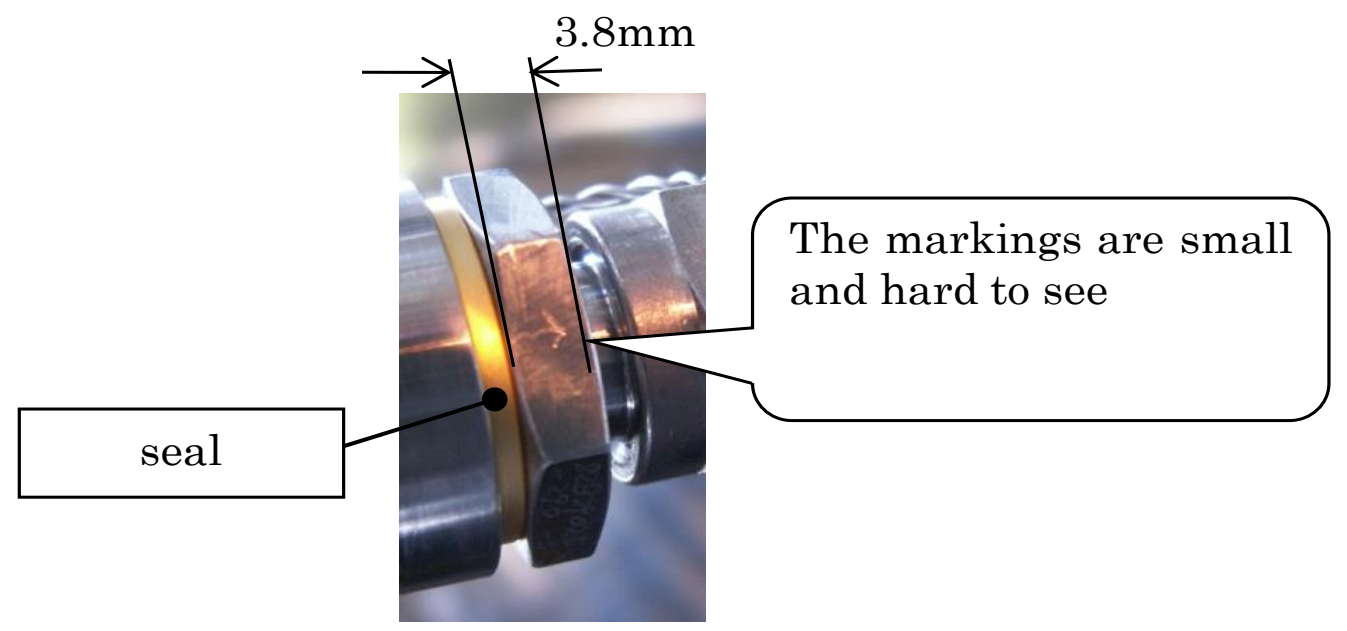

Figure 6. Orifice arrow marking.

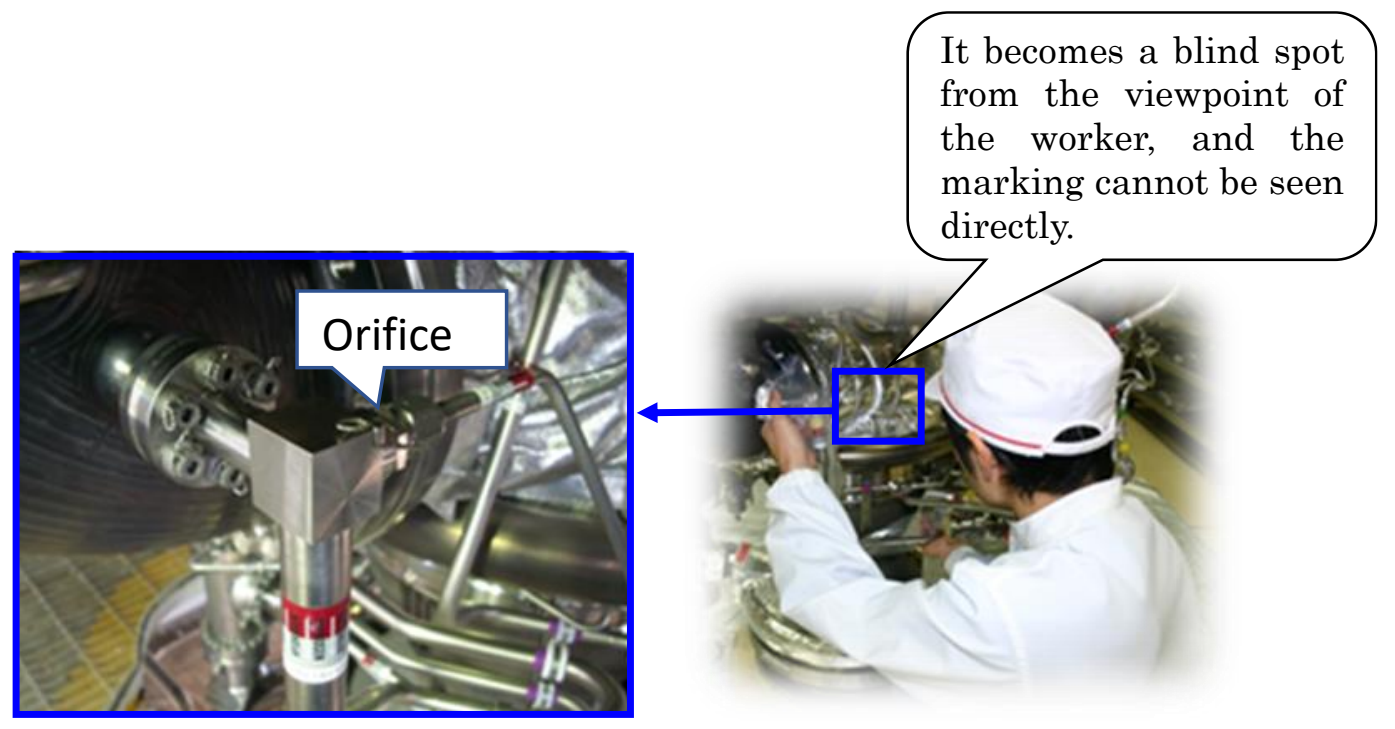

Figure 7. Orifice mounting work position.

Summarizing the above, following two misidentification risks during installation works which cause human errors due to the frustration avoidance behavior, are extracted:

A: The misidentification risk which is caused by wrong memories of workers.

$\mathrm{B}$ : The misidentification risk which is caused by wrong installed seal. 


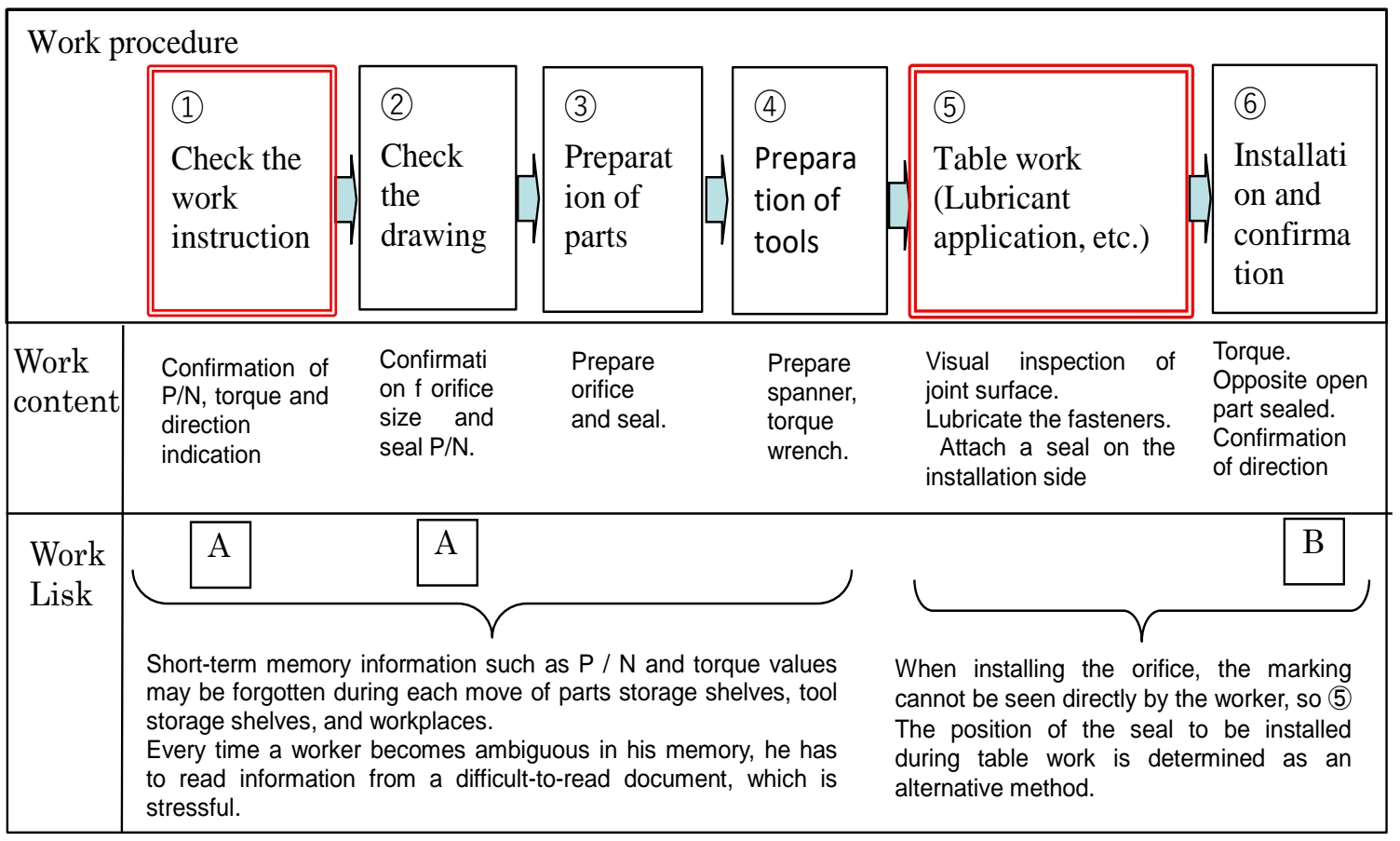

Figure 8. Work risks of skilled workers in orifice installation work.

Following countermeasures for decreasing above two risks are proposed:

Countermeasure of A: Prepare a piece of paper which summarizes procedures and specifications for the installation work.

Because the paper contains all necessary knowledge such as orifice identification numbers, required torque value, and work record columns for the installation work, workers can avoid reading a thick work procedure manual and flipping through different distant pages. Because the paper is prepared for each work and each worker does not undergo same work at the same time, workers can avoid waiting times which may disturb their workflows.

Previous procedure manuals prioritized editing efficiency, and organized information by function in categories such as parts, tools, procedures, and assembly drawings. Prioritizing the efficient acquisition of necessary information by skilled workers through countermeasures, we have rearranged the necessary information for each task. The total amount of information itself does not change, but due to the countermeasures, skilled workers used to check the manual three times on average in one task, but now it is only once. Even if the information medium changes from paper to electronic data due to the digitization of the work environment in the future, it is necessary to countermeasure perspective.

Countermeasure of B: Add direction marks on orifices which can be easily identified visually by workers.

Because conventional arrow markings on orifices are hard to identify visually and cannot be identified when workers cannot see them directly during their works, new direction marks which have followed two differences are added (Figure 9). 
(a) Machining orifices and the direction of orifice can be identified by hand touching. By erecting one side of the nut chamfer part, the direction can be determined with the fingertips. Such machining does not affect functions, strengths, and lives of orifices. Workers can identify the direction of orifices by hand touching when they cannot see them directly.

(b) Coloring on orifices and the direction of orifice can be easily identified visually. For workers, colorings are much easier for the direction identification than arrow marking scars.

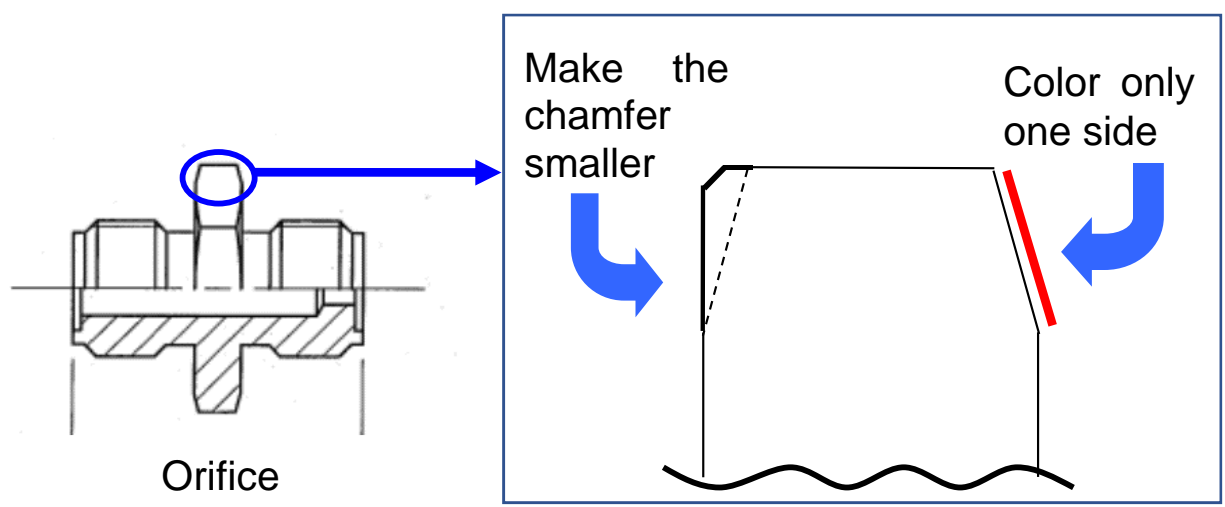

Figure 9. Orifice improvement measures.

This measure eliminates the need to use a hand mirror and a flashlight to look for markings and check their arrow orientation.

\section{Consideration}

There happen a various kind of nonconformities during production of aerospace equipment, such nonconformities are researched by the investigation board, and appropriate countermeasures are implemented. In some nonconformities concerning human errors of skilled workers, establishing effective countermeasures is difficult because these workers have sufficient knowledge, experience, and confidence in their works. In case of the installation orifices in a wrong direction to gas pipe assemblies of a space equipment, the cause of nonconformity was concluded as a simple carelessness according to the expert investigation board.

By using an ergonomic risk reduction method, checklists are prepared, 6 tasks of installation work are investigated by checklists, and ergonomic problems are discovered in 7 items of checklists. These items are summarized as following two issues:

(1) The poor usability of work procedure manual.

(2) The poor visibility in orifice mounting direction.

By considering how these two issues cause human errors, two misidentification risks during installation works are conducted and two countermeasures are derived from these two misidentification risks. These two countermeasures could not be derived from the conventional expert investigation board because the board does not consider the importance of skilled workers' frustration. This result shows us the importance of ergonomic human error risk reduction approach 
for the aerospace equipment manufacturing because its production work process cannot be automatized and aerospace equipment have to be high quality.

From a practical view point, we conclude that the ergonomic human error risk reduction method has following three advantages compared to other conventional methods:

\section{(a) Concreteness}

Although countermeasures of ergonomic method are concrete such as the preparation of one paper manual and the addition of color direction marks, those of other methods tend to depend on willpowers of workers.

\section{(b) Objectiveness}

Because skilled workers are supposed to have sufficient knowledge and mighty power of their work, causes of human error accidents are dismissed as a simple carelessness. However, this method can be objectively detected some problem from the ergonomic view point and improve the work environment.

\section{(c) Efficiency}

This method can detect problems and derive countermeasures in a short time when ergonomics experts and skilled workers can participate. Furthermore, this method can be applicable for a wide variety of manufacturing processes because the method is general-purpose.

Because the ergonomic human error risk reduction method can clarify true causes of nonconformities which are valid objectively and can establish concrete countermeasures which do not depend on the willpower of workers, the method can change workers' attitudes toward nonconformities. Skilled workers do not hide and deceive their mistakes and tend to reduce risks of their working environments. Because the ergonomic human error risk reduction method enables stakeholders to become aware of human error risk and improve their work environment, the method can enhance the resilience of organization (Komatsubara, 2016).

\section{Conclusions}

In this paper, we proposed an ergonomic human error risk reduction method for skilled workers in Japanese domestic liquid rocket engine manufacturing and confirmed the effectiveness of the method. By applying the method to the installation work of orifices to gas pipe assemblies of a space equipment, two objective countermeasures can be derived from a nonconformity from which the conventional method could not derive no effective countermeasure. This ergonomic human error risk reduction method can be applied to a wide variety of production processes which strongly depend on human skills and can enhance the resilience of organizations.

\section{Conflict of Interest}

The authors confirm that is no conflict of interest to declare for this publication.

\section{Acknowledgements}

Authors express their sincere thanks to the participants for demonstration of the case study and the authors really appreciate the effort of editors and refrtees in reviewing manuscript. 


\section{References}

Hashimoto, K. (1984). Safety ergonomics. Japan Industrial Safety \& Health Association.

International aerospace quality group. Japan aerospace quality group (2016). 9100 Quality Management System - Requirements for Aviation, Space and Defense Organizations, Japanese Industrial Standards.

International labor office in collaboration with the international ergonomics association (2010). Ergonomic checkpoints Second Edition, International Labour Office, Geneve.

Japan aerospace exploration agency (2017). Human factor analysis handbook. Jerg-0-018A, Appendix 1, JAXA, Tsukuba.

Karino, H. (1985). A consideration about stress and human error. Journal of Science of Labour, 61(1), 1-13.

Komatsubara, A. (2016). Safety ergonomic theory and technology. Maruzen. pp. 11-14.

Komatsubara, A. (1999). Prevention of skilled worker human error from cognitive ergonomics. Japan Sosiety for Safety Engineering, 38(6).

Kumashiro, M. (2008). Workplace improvement wisdom of occupational safety. Nikkagiren, Tokyo. pp. 8287.

Rasmussen, J. (1983). Skills, rules, and knowledge; signals, signs, and symbols, and other distinctions in human performance models. IEEE Transactions on System, Man, and Cybernetics, 13(3), 257-266. 